\title{
Restricting the Power of Cophonologies: A Representational Solution to Stem Allomorphy in Uspanteko
}

\author{
Björn Köhnlein, Yuhong Zhu \\ The Ohio State University
}

\section{Introduction}

Uspanteko, a Mayan language spoken in Guatemala, displays rich interactions between the location of stress, vowel quality, syllable weight and pitch accent (falling vs. level tone) in monomorphemic words. Furthermore, certain possessive prefixes in Uspanteko can change level to falling pitch accent within paradigms, which sometimes also triggers stress shifts from final to penultimate syllables. Such stress shifts then go hand in hand with shortening of long vowels in final syllables or with deletion of the second consonant in biconsonantal word-final coda clusters. In this paper, we argue that these apparently complex patterns of stem allomorphy can be successfully analyzed within a morpheme-based model of morphology, and that it is not necessary to refer to richer models. Our approach builds on two analytical claims:
Main analytical claims
a. Pitch-accent contrasts in Uspanteko are a surface exponent of a difference between trochaic feet (falling tone) and iambic feet (level tone), as proposed in Köhnlein (2019) for monomorphemic words.
b. Non-concatenative exponence in Uspanteko can be analyzed as an epiphenomenon of metrical affixation.

Our analysis contributes to several ongoing debates in the literature. First of all, our approach to nonconcatenative exponence is in line with principles of Generalized Non-Linear Affixation, as defined in, e.g., Bermúdez-Otero (2012) or Trommer \& Zimmermann (2014). We argue that our morpheme-based approach to the alternations is more restrictive than an earlier account by Bennett \& Henderson (2013; henceforth $\mathrm{B} \& \mathrm{H}$ ), who divide relevant items into several nominal cophonologies. Second, our foot-based analysis of the tonal patterns in Uspanteko builds on recent work on the phonological representation of tonal accent that calls into question the mainstream view that tonal contrasts within syllables have to follow from lexical tone (see, e.g., Hyman 2009). In doing so, it continues recent metrical work on, e.g., tonal accent in North Germanic (Morén-Duolljá 2013, Iosad 2016), West Germanic (Köhnlein 2011, 2016, Hermans 2012, Kehrein 2017), or Scottish Gaelic (Morison 2018). Third, by assuming that underlying representations can contain metrical templates, we contribute to the current reemergence of templatic morphology, which has not only been employed for the analysis of tonal accent (as in Köhnlein 2011, 2016, Morén-Duolljá 2013, Iosad 2016), but is also used in, e.g., Saba Kirchner $(2010,2013)$ to analyze reduplication. Our analysis is formalized in Optimality Theory (Prince \& Smolensky 1993, McCarthy \& Prince 1995). In this paper, we predominantly focus on alternations in items that surface with long vowels in isolation. Space restrictions prohibit us from providing a more comprehensive analysis of the patterns, but we believe this is sufficient to make our general points. Our complete account will be in Köhnlein \& Zhu (in preparation), where we will employ Stratal Optimality Theory (e.g. Bermúdez-Otero 2018) to account for certain derived-environment effects; we do not formalize these aspects here, but briefly discuss them in our analysis.

This paper is organized as follows: $\$ 2$ provides some essential facts and the tenets of the metrical analysis of Uspanteko bare roots in Köhnlein (2019). Patterns of stem allomorphy in long vowels are discussed in $§ 3$,

\footnotetext{
${ }^{*}$ For feedback and comments, we would like to thank the Phonetics-Phonology Discussion Group (Phonies), as well as the audiences at the $10^{\text {th }}$ North American Phonology Conference (NAPHC), the $26^{\text {th }}$ Manchester Phonology Meeting (MFM), and the 6th Annual Meeting on Phonology (AMP). The usual disclaimers apply.
} 
followed by a comparison with a previous analysis by Bennet \& Henderson (2013) and a short conclusion in $\S 4$.

\section{Basics of stress and pitch accent in bare roots}

Knowledge of some general stress and pitch accent patterns in simplex words, which B\&H also refer to as 'bare roots', and our general account thereof is helpful to understand our analysis of complex words. The basic patterns in (2) are adopted from B\&H. Underlining indicates stress; accent marks indicate the high tone of falling pitch accents, level pitch is unmarked; heavy syllables, which are long vowels (VV) or sequences of a short vowel plus a glottal stop plus another coda consonant (VPC), are treated as bimoraic:

Basic generalizations about distribution of stress and pitch accent in Uspanteko in simplex words Stress

a. Stress falls on one of the two last syllables - [t]fu.kex] 'cramp', [á.nim] 'woman', [lə.xo.ri]

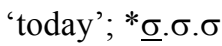

b. Heavy syllables are restricted to the final syllable and always receive stress - [al. $\left.\mathrm{k}^{2} \mathrm{waal}\right]$ 'son', [ku.wa?j] 'horse'; * $\mu \mu . \mu,{ }^{*} \mu . \mu \mu$

c. In disyllabic words with two light syllables, the vowel with the higher sonority receives stress - [á.nim] 'woman', [t]u.kex] 'cramp'; * $\underline{\mu}_{\text {Low-Son }} \cdot \mu_{\text {High-Son }}$

d. If vowels in disyllabic words with light syllables have equal sonority, either syllable can be stressed - [1́.wir] 'yesterday', [o.kof] 'mushroom'

e. In words with more than two syllables, stress is always final - [lə.xo.ri] 'today'; ${ }^{*} \underline{\sigma} . \sigma . \sigma,{ }^{*} \sigma . \underline{\sigma} . \sigma$

Pitch accent

f. Some words have a falling pitch accent in stressed syllables, where $\mathrm{H}$ is restricted to the penultimate vocalic mora of a word $-\left[\mathrm{kúuk}^{2}\right]$ 'squirrel', * $\mu . \underline{\mu}, * \underline{\mu} \underline{\mu}$

g. Words with penultimate stress always have a falling pitch accent - [á.nim] 'woman'; * $\underline{\mu} . \mu$

h. Long vowels in polysyllabic words never have falling pitch, but always level pitch - [tu.kuur] 'owl'; * $\mu . \underline{\mu \mu}$

i. Some long vowels in monosyllabic have a falling pitch accent, some have level pitch $-\left[\underline{k u ́ u k}^{2}\right]$ 'squirrel', [t] uun] 'lime (mineral)'

j. Words with a moraic glottal stop never have a pitch accent $-[\underline{\mathrm{ka} n}]$ 'animal', ${ }^{*} \underline{\mu} \mu^{?} \mathrm{C}$

Assuming the foot inventory by Kager (1993), we adopt from Köhnlein (2019) that the language contrasts moraic trochees (built directly on moras) and (default) syllabic iambs (built on syllables); the general contrast between iambs and trochees is already proposed in B\&H. We also adopt from Köhnlein (2019) that the tonal contrasts between trochees and iambs derive from differences in the mapping of a post-lexical HL tonal melody to these diverse structures. The essential analytical claim is that, along the lines of de Lacy (2002), $\mathrm{H}$ is avoided in weak positions, and $\mathrm{L}$ in strong positions. In moraic trochees $(3 \mathrm{a})$, the first mora is the head and thus receives $\mathrm{H}$; the second mora is the dependent, and thus receives $\mathrm{L}$. In different types of syllabic iambs (3b-d), on the other hand, the syllable node is the foot head. Both moras are licensed by the foot head, indicated with superscript pluses. Since L is prohibited in strong positions, it is blocked from both moras in the stressed iambic syllable, resulting in a high-level tone. Note that only bimoraic vocalic syllables can realize a pitch accent contrast. Words with moraic glottal stops can never have a falling pitch accent $(2 \mathrm{j})$ because the pitch accent contrast requires two sonorant moras to be realized.

Tonal mapping in trochaic feet $(a, b)$ and iambic feet $(c, d)$<smiles>CC[In][I+]</smiles>

a.<smiles>[I+]C1C[O+]O[In]1</smiles>

b.<smiles>[In]O[O+]O[InH]</smiles>

c.

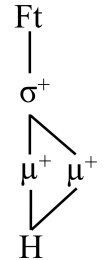

d. 


\section{Stem allomorphy under possessive prefixation}

This section provides our metrical analysis of stem allomorphy in long vowels upon possessive prefixation. We introduce the basic generalizations for simplex forms with long vowels in §3.1. In §3.2, we discuss our representational assumptions. In $\S 3.3$, we show how prefixes and roots interact in the grammar. In $\S 3.4$, we briefly discuss two other groups of items that show variation: items ending in glottal stops plus another consonant, and disyllabic words with light final stressed syllables. In $\S 3.5$, we provide a summary of our analysis and certain derived-environment effects that we do not analyze formally in this paper, but will treat in Köhnlein \& Zhu (in preparation).

3.1 Basic generalizations In Uspanteko, certain possessive prefixes can affect stress, pitch accent, and vowel length in stem forms (B\&H for an analysis where this behavior is linked to the assignment of genitive case). Some examples with the prefixes /in-/ 'my' (before C) or /aw-/ 'your' (before V) are given in (4) below (data from B\&H, Can Pixabaj 2006). The alternations can be divided into two general patterns, one that affects roots with high-level pitch (iambic feet in our approach, Pattern A), and one that affects roots with falling pitch accent (trochaic feet in our approach, Pattern B).

Possessive stem allomorphy in Uspanteko for items with long vowels in bare roots
a. Pattern A1: [oox] [aw-óox] 'avocado' 'your avocado'
b. Pattern A2: [teem] [ín-tem] 'chair' 'my chair'
c. Pattern A3: [keem] [ [in-keem] 'weaving' 'my weaving'
d. Pattern B: $\left[\right.$ kúuk $\left.^{2}\right] \sim\left[\right.$ in-kúuk $\left.{ }^{2}\right]$ 'squirrel' 'my squirrel'

Patterns A1-3 in (4a-c) indicate the three attested patterns for items with long vowels and high-level pitch accent in isolation. Pattern A1 (4a) shows a change in pitch accent after affixation: [oox] with a high level pitch accent turns into [aw-óox] with a falling pitch accent; vowel length and stress are retained. Pattern A2 (4b) shows a change in stress and pitch accent: Stress moves to the prefix after affixation, and the pitch accent changes from high level to falling; the root vowel is shortened when affixed. Pattern A3 (4c) retains the highlevel pitch accent, vowel length, and the position of stress. Lastly, Pattern B (4d) provides the only attested pattern for items with long vowels with falling pitch in isolation: Such items always retain stress, falling pitch accent, and vowel length.

3.2 Analysis: representations To account for the allomorphy patterns discussed in $\S 3.1$, we first propose that possessive prefixes are lexically specified with segmental information (/SEG/, differs depending on the morpheme) and a floating bimoraic trochaic foot template (5a). (5b-d) show the underlying representations for iambic words that surface with long vowels and high-level pitch in isolation. (5b, corresponding to Pattern A1) has a vowel associated with two moras; (5c, Pattern A2) a non-moraic vowel plus two floating moras ${ }^{1}$; $(5 \mathrm{~d}$, Pattern A3) is a bimoraic vowel associated with a syllabic iamb; (5e, Pattern B) shows a bimoraic vowel associated with a moraic trochee. We argue that this is the exhaustive list of representations with long vowels that undergo prefixation at the word level, that is, after having passed the stem level derivation. ${ }^{2}$

\footnotetext{
${ }^{1}$ For Pattern A2, an underlying monomoraic vowel plus a floating mora would lead to the same outcome.

${ }^{2}$ Note that there are more logical possibilities, viz. roots with floating trochees and iambs. Essentially, we argue that such floating feet will be deleted at the stem level, that is, only associated templates (as in ( $5 \mathrm{~d}, \mathrm{e})$ ) are preserved; again, we refer to Köhnlein \& Zhu (in preparation) for details of the analysis.
} 


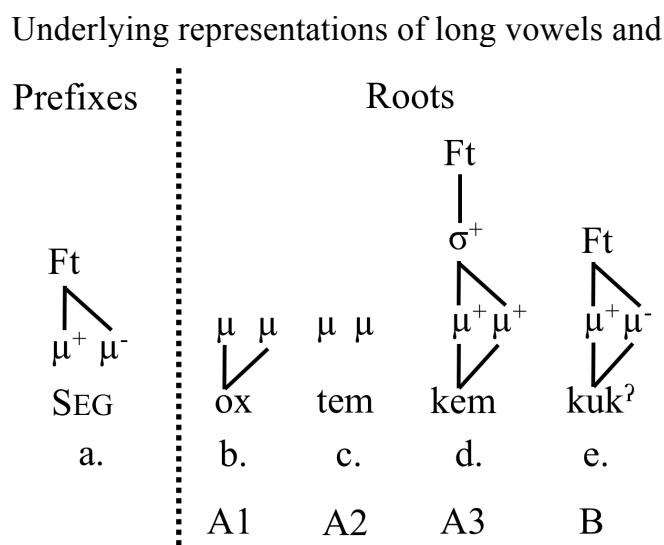

\subsection{Analysis: grammar}

3.3.1 Pattern A1: [oox] [a.wóox] The surface representations for roots of the type $/ \mathrm{o}_{\mu \mu} \mathrm{x} /(5 \mathrm{~b}$, Pattern A1) are shown in (6). Such roots have two associated moras in their underlying representation, and these associations have to be preserved throughout the derivation. In isolation, the word will receive a default iambic foot and surface as [oox] with high-level pitch. When combined with the possessive prefix (5a), however, the templatic trochaic foot will override the default footing, and the word will surface with a trochaic foot on the final, stressed syllable [a.wóox], leading to a falling pitch accent; the first syllable remains unparsed.

Representations for roots following Pattern A1

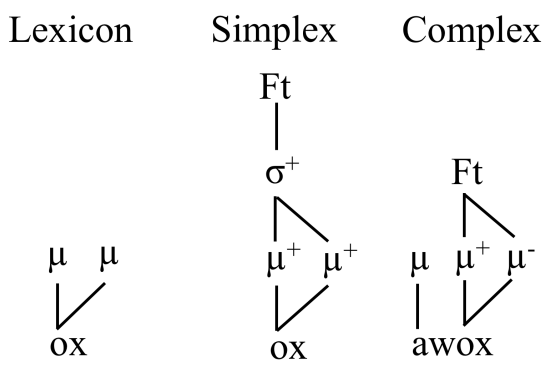

The patterns are implemented into (word-level) OT as follows. In the simplex form, Pattern-A1 items will surface as iambic because the constraint IAMB (7) outranks the constraint TROCHEE (8).

(7) IAMB: Assign one violation mark for each foot in the output that is not an iamb.

(8) TROCHEE: Assign one violation mark for each foot in the output that is not a trochee.

Preserving association lines between moras and segments can be attributed to the constraint MAX-LINK$\mu[\mathrm{SEG}]$ (Morén 2001), which is defined in (9); this constraint ensures that the root syllable will always surface with a bimoraic vowel.

(9) MAX-LinK- $\mu[\mathrm{SEG}]$ : Assign one violation mark for every association line in the input between a mora and a segment that does not have a correspondent in the output. 
The interaction of these constraints is shown in the tableau in (10). Candidate (10a) wins because parsing the bare root as an iamb (indicated as ' ++ ' on the stressed long vowel) is preferable over parsing it as a trochee (10b, indicated with ' + -' on the stressed long vowel).

\begin{tabular}{|c|c|c|c|}
\hline & & & \\
\hline & & & \\
\hline 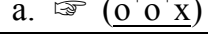 & & & $*$ \\
\hline b. $\quad\left(\mathrm{o}^{+} \mathrm{O}^{-} \mathrm{x}\right)$ & & $* !$ & \\
\hline c. $\quad\left(\mathrm{O}^{+} \mathrm{x}\right)$ & $* !$ & & \\
\hline
\end{tabular}

As indicated in (5a), the possessive prefix contains a trochaic template in its underlying representation. A high-ranked constraint preserving foot heads (HD-MATCH (FT); McCarthy 1995, 2000; Köhnlein 2016, 2019) guarantees that the templatic trochaic foot is realized on the surface:

HD-MATCH (FT): Assign a violation mark for every foot head in the input that is not preserved in the output.

Furthermore, as already established by B\&H, ALL-FT-R excludes all feet that are not aligned with the right edge of the prosodic word, as shown in (12); to keep the overall size of the tableaux manageable, we do not include low-ranked ALL-FT-L, but will provide it in the Hasse diagram in $§ 3.5$.

ALL-FT-R: Assign a violation mark for each foot that is not aligned with the right edge of a prosodic word.

Satisfying high-ranked MAX-LINK- $\mu$ SEG], HD-MATCH (FT), and ALL-FT-R means that the first syllable will have to be left unparsed; this not only violates IAMB but also a constraint that requires all moras in the word to be parsed by a foot:

PARSE: Assign one violation mark for each mora that is not parsed into a foot.

With these constraints in mind, consider the tableau in (14). Candidate (14a), the winner, preserves vowel length and incorporates the templatic trochee at the right edge; it only violates lower-ranked PARSE and IAMB. Candidate (14b) with a full parse and a generally unmarked iambic foot fatally violates HD-MATCH (FT); Candidate (14c) fails to preserve the association between the mora and the segment, which violates highranked MAX-LINK- $\mu[\mathrm{SEG}]$; Candidate (14d) has a trochaic foot that is not aligned with the right edge, violating undominated ALL-FT-R.

\begin{tabular}{|c|c|c|c|c|c|c|}
\hline $\mathrm{aw}-\left(\mu^{+} \mu^{-}\right)+\mathrm{o}_{\mu \mu} \mathrm{x}$ & $\begin{array}{c}\text { MAX-LINK- } \\
\mu[\mathrm{SEG}]\end{array}$ & HD-MATCH (FT) & ALL-FT-R & PARSE & IAMB & TROCHEE \\
\hline a. $\rightarrow \cdot\left(\right.$ wó $\left.^{+} \mathrm{o}^{-} \mathrm{x}\right)$ & & & & $*$ & $*$ & \\
\hline b. $\quad\left(\mathrm{a}^{-} \cdot \mathrm{wo}^{+} \mathrm{O}^{+} \mathrm{x}\right)$ & & $* !$ & & & & $*$ \\
\hline c. $\quad\left(a^{+} \cdot\right.$ wo $\left.^{-} \mathrm{x}\right)$ & $* !$ & & & & $*$ & \\
\hline d. $\quad\left(a^{+} \cdot w^{-}\right)$ox & & & $* !$ & $*$ & $*$ & \\
\hline
\end{tabular}

3.3.2 Pattern A2: [teem] [ín.tem] Consider the surface representations for roots of the type /tem + $\mu \mu /(5 b$, Pattern A2) in (15). Roots belonging to Pattern A2 have very similar underlying representations to those of Pattern A1, except that the two underlying moras are floating. In isolation, the two moras will be associated with the vowel, and the word will receive an iambic foot, similar to bare roots of Pattern A1. Upon prefixation, however, there is no particular 'pressure' to associate both moras with the root vowel - since the moras are floating, the root vowel and the affix vowel can receive one mora each; this ensure that all moras in the word can be parsed in one trochaic foot. On the surface, affixed [ín.tem] thus appears as if its root vowel is shortened compared to simplex [teem]. In this sense, the pattern bares similarities to what is sometimes referred to as 'trochaic shortening' (e.g. Hayes 1995). 


Representations for roots following Pattern $\mathrm{A} 2$
Lexicon

For the OT implementation, we need to ensure that the floating moras are associated with vowels. We assume that this follows from a high-ranked constraint militating against floating moras, *FLOAT, which is defined in (16). *FLOAT dominates a constraint against introducing new association lines (DEP-LINK- $\mu[$ SEG]), which we omit for reasons of space; again, it will be included in the Hasse diagram in $§ 3.5$.

*FLOAT: Assign one violation mark for every floating mora in the output.

An OT tableau for the simplex form [teem] is provided in (17). Candidate (17a) wins because it associates both moras (satisfying *FLOAT) and forms a default iambic foot (satisfying IAMB). Candidate (17b) with a trochaic foot is out because it violates IAMB; candidate (17c) loses because it fails to associate one of the two floating moras.

/tem $+\mu \mu / \rightarrow[$ teem]
\begin{tabular}{|l||c|c|c|c|c|c|c|}
\hline tem $+\mu \mu$ & $\begin{array}{c}\text { MAX-LINK- } \\
\mu[\text { SEG }]\end{array}$ & $\begin{array}{c}\text { HD-MATCH } \\
(\text { FT })\end{array}$ & $\begin{array}{c}\text { ALL- } \\
\text { FT-R }\end{array}$ & $*$ FLOAT & PARSE & IAMB & TROCHEE \\
\hline a. $\left(\right.$ te $\left.^{+} \mathrm{e}^{+} \mathrm{m}\right)$ & & & & & & & $*$ \\
\hline b. $\quad\left(\mathrm{te}^{+} \mathrm{e}^{-} \mathrm{m}\right)$ & & & & & & $* !$ & \\
\hline c. $\quad\left(\underline{\mathrm{te}^{+} \mathrm{m}}\right) \mu$ & & & & $* !$ & & & \\
\hline
\end{tabular}

The OT evaluation of the corresponding prefixed form is shown in (18). We assume that the two moras associate with the template can coalesce with the two moras that are underlyingly present, so we will only assess the association of two moras, rather than of four. Candidate (18a) is the winner because it realizes the templatic trochee and parses all moras. Candidate (18b), which incorporates the prefix trochaic template and also preserves the long vowel, loses because it fails to parse all moras. Finally, the iambic candidate (18c) does not realize the templatic trochee, which means that it is out since HD-MATCH (FT) outranks IAMB.

\begin{tabular}{|c|c|c|c|c|c|c|c|}
\hline $\begin{array}{r}\text { in- }\left(\mu^{+} \mu^{-}\right)+\text {tem } \\
+\mu \mu \\
\end{array}$ & $\begin{array}{c}\text { MAX-LINK- } \\
\mu[\text { SEG }]\end{array}$ & $\begin{array}{l}\text { HD-MATCH } \\
\text { (FT) }\end{array}$ & $\begin{array}{l}\text { ALL- } \\
\text { FT-R }\end{array}$ & *FLOAT & PARSE & IAMB & TROCHEE \\
\hline a. $\left(\underline{1^{+} n} \cdot t^{-} m\right)$ & & & & & & * & \\
\hline b. in. $\left(\right.$ té $\left.^{+} \mathrm{e}^{-} \mathrm{m}\right)$ & & & & & *! & * & \\
\hline 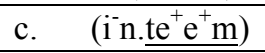 & & $* !$ & & & & & * \\
\hline
\end{tabular}

3.3.3 Pattern A3: [keem] [in. keem] Our representations for Pattern A3 are shown in (19). There is no change in stress or pitch accent/foot structure between the simplex and the complex form, which are always realized with a high-level pitch accent. In our metrical approach, this implies that both surface forms contain an iambic foot. We propose that this stability is due to lexically specified foot structure, i.e., Pattern A3 roots have lexically stored iambs. These lexically stored feet cannot be overridden by the templatic prefix trochee. 


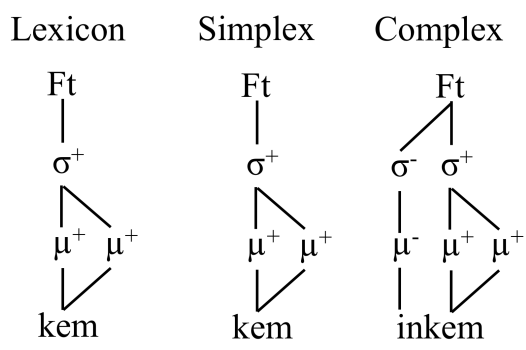

In OT, this outcome can be derived with the constraints established so far. Tableaux for [keem] and [in-keem] are shown in (20) and (21), respectively. The tableau in (20) seems fairly straightforward: The iambic candidate (20a) wins not only because of the stored iambic template, but also because iambs are the default feet anyway. In (21), candidate (21a) wins because if two underlying feet compete, the iambic foot will be selected, as it satisfies PARSE, and is also favored by the ranking IAMB $>>$ TROCHEE. ${ }^{3}$

$/\left(\mathrm{ke}^{+} \mathrm{e}^{+} \mathrm{m}\right) / \rightarrow[\mathrm{keem}]$

\begin{tabular}{|c|c|c|c|c|c|c|c|}
\hline$\left(\underline{\mathrm{ke}^{+} \mathrm{e}^{+} \mathrm{m}}\right)$ & $\begin{array}{c}\text { MAX-LINK- } \\
\mu[\text { SEG }]\end{array}$ & $\begin{array}{c}\text { HD-MATCH } \\
(\mathrm{FT}) \\
\end{array}$ & $\begin{array}{l}\text { ALL- } \\
\text { FT-R } \\
\end{array}$ & *FLOAT & PARSE & IAMB & TROCHEE \\
\hline a. $\left(\mathrm{ke}^{+} \mathrm{e}^{+} \mathrm{m}\right)$ & & & & & & & $*$ \\
\hline b. $\quad\left(\mathrm{ké}^{+} \mathrm{e}^{-} \mathrm{m}\right)$ & & $* !$ & & & & $*$ & \\
\hline
\end{tabular}

\begin{tabular}{|c|c|c|c|c|c|c|c|}
\hline $\begin{array}{r}\text { in }-\left(\mu^{+} \mu^{-}\right)+ \\
\left(\mathrm{ke}^{+} \mathrm{e}^{+} \mathrm{m}\right)\end{array}$ & $\begin{array}{c}\text { MAX-LINK- } \\
\mu[\mathrm{SEG}]\end{array}$ & $\begin{array}{c}\text { HD-MATCH } \\
(\mathrm{FT})\end{array}$ & $\begin{array}{l}\text { ALL- } \\
\text { FT-R }\end{array}$ & *FLOAT & PARSE & IAMB & TROCHEE \\
\hline a. (in. $\left.\mathrm{ke}^{+} \mathrm{e}^{+} \mathrm{m}\right)$ & & $*$ & & & & & $*$ \\
\hline b. $\quad$ in. $\left(\mathrm{ké}^{+} \mathrm{e}^{-} \mathrm{m}\right)$ & & $*$ & & & $* !$ & $*$ & \\
\hline
\end{tabular}

3.3.4 Pattern B: [kúuk? $] \sim\left[\right.$ in. $\left.k k_{u} u k^{2}\right] \quad$ Representations for Pattern B are given in (22). This pattern differs from Patterns A1-3 because it is the only pattern where a long vowel carries a falling pitch accent in isolation. In our approach, this follows from the fact that the underlying form must be stored with a trochaic foot, since it is the marked foot. This foot has to be preserved on the surface.

\section{Representations for roots following Pattern B}

Lexicon Simplex Complex

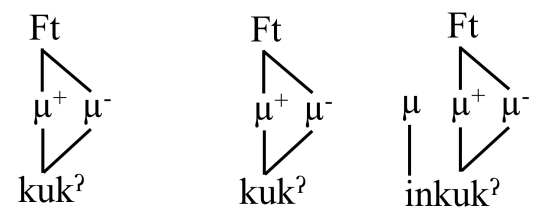

Consider first the OT implementation for the simplex form in (23). Candidate (23a) is the winner because unlike the losing candidate (23b) - it preserves the trochaic template in the input, satisfying HD-MATCH (FT). (23)

\begin{tabular}{|c|c|c|c|c|c|c|c|}
\hline$\left(\underline{\mathrm{ku}^{+} \mathrm{u}^{-} \mathrm{k}^{2}}\right)$ & $\begin{array}{c}\text { MAX-LINK- } \\
\mu[\text { SEG }]\end{array}$ & $\begin{array}{c}\text { HD-MATCH } \\
(\mathrm{FT})\end{array}$ & $\begin{array}{l}\text { ALL- } \\
\text { FT-R }\end{array}$ & *FLOAT & PARSE & IAMB & TROCHEE \\
\hline a. $\left(\mathrm{ku}^{+} \mathrm{u}^{-} \mathrm{k}^{2}\right)$ & & & & & & $*$ & \\
\hline b. $\quad\left(\mathrm{ku}^{+} \mathrm{u}^{+} \mathrm{k}^{\mathrm{2}}\right)$ & & $* !$ & & & & & $*$ \\
\hline
\end{tabular}

\footnotetext{
${ }^{3}$ We assume here that MAX-LINK- $\mu[\mathrm{SEG}]$ is satisfied as long as the surface form has a bimoraic vowel, even in the candidate where the foot structure is changed. This has no bearing on the analysis.
} 
For the derivation of the complex form, changing the trochaic foot structure into a bimoraic foot distributed over two syllables would involve vowel shortening, which would result in a violation of MAX-LINK- $\mu[$ SEG]. Therefore, candidate (24c), which parses all moras in one bimoraic trochaic foot, loses to the winning candidate (24a). Similar to the evaluation in (23), candidate (24b) loses since it fails to preserve the trochaic template.

\begin{tabular}{|c|c|c|c|c|c|c|c|}
\hline in- $\left(\mu^{+} \mu^{-}\right)+\left(\mathrm{ku}^{+} \mathrm{u}^{-}{ }^{2}\right)$ & $\begin{array}{c}\text { MAX-LINK- } \\
\mu[\text { SEG] }\end{array}$ & $\begin{array}{l}\text { HD-MATCH } \\
\text { (FT) }\end{array}$ & $\begin{array}{l}\text { ALL- } \\
\text { FT-R }\end{array}$ & $\begin{array}{c}* \text { FLO } \\
\text { AT }\end{array}$ & PARSE & $\begin{array}{l}\text { IA } \\
\text { MB }\end{array}$ & TROCHEE \\
\hline a. in. $\left(\mathrm{ku}^{+} \mathrm{uk}^{-}\right)$ & & & & & $*$ & $*$ & \\
\hline b. $\quad\left(\mathrm{in}^{-} \mathrm{ku} \mathrm{u}^{+} \mathrm{u}^{+} \mathrm{k}^{2}\right)$ & & $* !$ & & & & & $*$ \\
\hline c. $\quad\left(\underline{(i+}^{+} \mathrm{n} \cdot \mathrm{ku}^{-} \mathrm{k}^{2}\right)$ & $* !$ & & & & & & \\
\hline
\end{tabular}

3.4 Additional patterns In this section, we briefly discuss two other relevant patterns where we find less variation than in items that surface with long vowels in isolation. First, there are two patterns of allomorphy involving roots with short vowels followed by glottal stops and another consonant. These patterns are provided in (25); we will refer to them as $\mathrm{C} 1$ and $\mathrm{C} 2$, respectively. As established by $\mathrm{B} \& \mathrm{H}$, sequences of a short vowel plus a glottal stop plus another coda consonant (V?C) are the only sequences aside from long vowels that are treated as heavy in the language, and therefore can be considered bimoraic (Köhnlein 2019 for an analysis of this pattern based on final consonant extrametricality). As mentioned in $\$ 2$, bimoraic syllables with moraic glottal stops do not show a pitch accent contrast. In our metrical approach, this can be attributed to the glottal stop not being a sonorant mora, and therefore being unable to host a tone.

Possessive stem allomorphy in Uspanteko for items with $\mathrm{PC}$ coda clusters

a. Pattern C1: [ka?n] $\sim$ [in-ka?n] 'animal' 'my animal'

b. Pattern C2: [ti?n] [ín-ti? ] 'meat' 'my meat'

In Pattern $\mathrm{C} 1$, the prefix does not influence the realization of the stem, which we take to mean that $/ \mathrm{kaPn} /$ is underlyingly represented with a foot template, similar to Patterns A3 ([keem] $\sim[$ in-keem $]$ ) and B ([kúuk $\left.{ }^{2}\right] \sim$ [in-kúuk $\left.{ }^{2}\right]$ ). This might be represented as two associated moras, an iambic foot, or a trochaic foot - as far as we can judge based on the available data, all these representations would lead to the same surface realizations. We demonstrate this in $(26,27)$ with an input containing an associated iamb. As shown, all the evaluation could do is to rule out candidates with changes in metrical structures (26b, 27b). Whether the root is underlyingly an iamb or a trochee, however, does not contribute to any difference on the surface: the nucleus [a] will host a high tone either way, while the moraic glottal stop [?] will not be able to host any tonal material.

$/\left(\mathrm{ka}^{+} \mathrm{P}^{+} \mathrm{n}\right) / \rightarrow[\mathrm{ka} \mathrm{n}]$
\begin{tabular}{|l||c|c|c|c|c|c|c|}
\hline$\left(\underline{\mathrm{ka}^{+} \mathrm{P}^{+} \mathrm{n}}\right)$ & $\begin{array}{c}\text { MAX-LINK- } \\
\mu[\mathrm{SEG}]\end{array}$ & $\begin{array}{c}\text { HD-MATCH } \\
(\mathrm{FT})\end{array}$ & $\begin{array}{c}\text { ALL- } \\
\text { FT-R }\end{array}$ & *FLOAT & PARSE & IAMB & TROCHEE \\
\hline \hline a. $\left(\mathrm{ka}^{+} \mathrm{P}^{+} \mathrm{n}\right)$ & & & & & & & $*$ \\
\hline b. $\left(\underline{\mathrm{ka}^{+} \mathrm{r}}\right)$ & $* !$ & $*$ & & & & $*$ & \\
\hline
\end{tabular}




\begin{tabular}{|c|c|c|c|c|c|c|c|}
\hline $\begin{array}{r}\text { in- }\left(\mu^{+} \mu^{-}\right)+ \\
\left(\mathrm{ka}^{+} \mathrm{P}^{+} \mathrm{n}\right) \\
\end{array}$ & $\begin{array}{c}\text { MAX-LINK- } \\
\mu[\text { SEG }]\end{array}$ & $\begin{array}{l}\text { HD-MATCH } \\
\text { (FT) }\end{array}$ & $\begin{array}{l}\text { ALL- } \\
\text { FT-R }\end{array}$ & $\begin{array}{c}* \text { FLO } \\
\text { AT }\end{array}$ & $\begin{array}{l}\text { PAR } \\
\text { SE }\end{array}$ & IAMB & TROCHEE \\
\hline a. $\left(\mathrm{i}^{-} \mathrm{n} \cdot \mathrm{ka}^{+} \mathrm{P}^{+} \mathrm{n}\right)$ & & * & & & & & * \\
\hline b. $\quad$ in. $\left(\mathrm{ka}^{+} \mathrm{P}^{-} \mathrm{n}\right)$ & & * & & & $* !$ & * & \\
\hline
\end{tabular}

Pattern $\mathrm{C} 2$ shows deletion of the final consonant, stress shift to the penultimate, and introduces a falling pitch accent in the complex form. Structurally, this pattern is virtually identical to Pattern A2 ([teem] [ín-tem]). If we assume that $/ \mathrm{ti} \mathrm{n} /$ is stored without associated moras, consonant deletion serves to make the second syllable monomoraic (since [?] is only moraic in [?C\#] clusters). As a result, the bimoraic templatic trochee (with falling tone) can be realized spanning both syllables, thereby ensuring that all moras are parsed by a foot. Regarding the OT implementation, the constraints established so far are sufficient to derive the 'correct' outcome; for the sake of completeness, we also introduce a low-ranked constraint against consonant deletion (MAX-C) in the tableau for the suffixed form in, which will have to be dominated by PARSE:

(28): MAX-C: Assign one violation mark for every consonant in the input that does not have a correspondent in the output.

In isolation, /ti?n/ will surface with a default iamb [ti?n] (29a). When prefixed, the optimal candidate (30a) ensures a full parse of both syllables, while incorporating the templatic trochee. (30b) fails to parse both syllables, while (30c) fails to preserve the prefix trochaic template.

\begin{tabular}{|c|c|c|c|c|c|c|c|}
\hline tem $+\mu \mu$ & $\begin{array}{c}\text { MAX-LINK- } \\
\mu[\mathrm{SEG}]\end{array}$ & $\begin{array}{l}\text { HD-MATCH } \\
\text { (FT) }\end{array}$ & $\begin{array}{l}\text { ALL- } \\
\text { FT-R }\end{array}$ & *FLOAT & PARSE & IAMB & TROCHEE \\
\hline a. $\left(\mathrm{ti}^{+} \mathrm{P}^{+} \mathrm{n}\right)$ & & & & & & & * \\
\hline b. $\quad\left(\mathrm{ti}^{+} \mathrm{T}^{-} \mathrm{n}\right)$ & & & & & & $* !$ & \\
\hline
\end{tabular}

\begin{tabular}{|c|c|c|c|c|c|c|c|c|}
\hline $\begin{array}{r}\text { in- }\left(\mu^{+} \mu^{-}\right)+\operatorname{tiPn} \\
+\mu \mu \\
\end{array}$ & $\begin{array}{c}\text { MAX-LINK- } \\
\mu[\mathrm{SEG}]\end{array}$ & $\begin{array}{l}\text { HD-MATCH } \\
\text { (FT) }\end{array}$ & $\begin{array}{l}\text { ALL- } \\
\text { FT-R }\end{array}$ & *FLOAT & PARSE & IAMB & MAX-C & TROCHEE \\
\hline a. $\left(i^{+} n \cdot t^{-}\right.$? $)$ & & & & & & $*$ & $*$ & \\
\hline b. in. $\left(\mathrm{ti}^{+} \mathrm{P}^{-} \mathrm{n}\right)$ & & & & & $* !$ & * & & \\
\hline c. $\quad\left(\mathrm{in}^{-} \mathrm{t} \cdot \mathrm{ti}^{+} \mathrm{P}^{+} \mathrm{n}\right)$ & & $* !$ & & & & & & $*$ \\
\hline
\end{tabular}

Furthermore, there are polysyllabic words with two light syllables that display a stress shift to the penultimate syllable (Pattern D). An example is shown in (30). We assume that such items surface with default iambic feet in isolation, which is overwritten by the trochaic template associated with certain prefixes, leading to penultimate stress and falling pitch accent.

$$
\text { Pattern D: [te.leb] [in-té.le6] 'shoulder' 'my shoulder' }
$$

The simplex and complex evaluations for Pattern D words are given in (32) and (33), respectively. In isolation, the default iamb (32a) wins again. During prefixation, however, the templatic trochee is incorporated on the right edge of the word, leading to a stress shift (33a). The non-optimal Candidate (33b) contains a trochee not right-aligned, critically violating ALL-FT-R; (33c), on the other hand, is not optimal due to the loss of the templatic trochee, violating $\mathrm{HD}-\mathrm{MATCH}(\mathrm{FT})$. 


\begin{tabular}{|c|c|c|c|c|c|c|c|}
\hline tele $6+\mu \mu$ & $\begin{array}{c}\text { MAX-LINK- } \\
\mu[\mathrm{SEG}]\end{array}$ & $\begin{array}{c}\text { HD-MATCH } \\
(\mathrm{FT})\end{array}$ & $\begin{array}{l}\text { ALL- } \\
\text { FT-R }\end{array}$ & *FLOAT & PARSE & IAMB & TROCHEE \\
\hline a. $\rightarrow\left(\mathrm{te}^{-} \cdot 1 \mathrm{e}^{+} \mathrm{b}\right)$ & & & & & & & $*$ \\
\hline b. $\quad\left(\right.$ té $\left.^{+} \cdot 1 \mathrm{e}^{-} 6\right)$ & & & & & & $* !$ & \\
\hline
\end{tabular}

\begin{tabular}{|c|c|c|c|c|c|c|c|}
\hline $\begin{array}{r}\text { in- }\left(\mu^{+} \mu^{-}\right)+\text {tele6 } \\
+\mu \mu\end{array}$ & $\begin{array}{c}\text { MAX-LINK- } \\
\mu[\mathrm{SEG}]\end{array}$ & $\begin{array}{c}\text { HD-MATCH } \\
(\mathrm{FT})\end{array}$ & $\begin{array}{l}\text { ALL- } \\
\text { FT-R }\end{array}$ & *FLOAT & PARSE & IAMB & TROCHEE \\
\hline 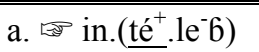 & & & & & $*$ & $*$ & \\
\hline b. $\quad\left(i^{+}\right.$n.te $) \cdot 1 \mathrm{le} 6$ & & & $* !$ & & $*$ & * & \\
\hline c. $\quad$ in. $\left(\mathrm{te}^{-} \cdot \mathrm{e}^{+} \mathrm{b}\right)$ & & $* !$ & & & $*$ & & $*$ \\
\hline
\end{tabular}

3.5 Summary of our analysis In this section, we have presented an analysis of allomorphy patterns in Uspanteko in a morpheme-based approach to morphology. Surface exponence of stress and pitch accent has been attributed to the interaction between a trochaic template associated with certain possessive prefixes, and underlying metrical material of the respective roots. Our combined constraint rankings are provided in the Hasse diagram in (34). As indicated in the text, the constraints AlL-FT-L and DEP-LinK-[SEG] were not provided in the tableaux for reasons of space, but are included here.

Hasse diagram of the established constraint rankings
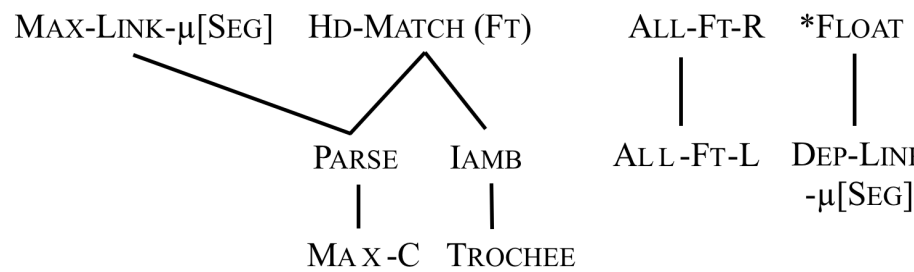

ALL-FT-L DEP-LINK $-\mu[\mathrm{SEG}]$

Lastly, we would like to point out that prefixed words can violate certain restrictions that monomorphemic words have to obey. For instance, stress in words with more than three syllables is always final in bare roots (as described by B\&H), but examples like [in-té.leb] show that these effects can be overridden in morphologically complex words (cf. *[lə.xó.ri]). Another example ties to the sonority-sensitive stress pattern illustrated in (2d). In simplex words with two light syllables, stress is always attracted to the higher-sonority vowel (cf. *[t]ú.kex]). This restriction is, however, disregarded in the complex word [ín.tem]. In Köhnlein \& Zhu (in preparation), we argue that these (and certain other) derived-environment effects can best be captured in a stratal model of OT.

\section{Discussion and conclusion}

We have presented a morpheme-based account of prefixed-induced stem allomorphy patterns in Uspanteko, attributing the stress and pitch accent patterns to the interaction of contrastive foot structure. Our approach to Uspanteko stem allomorphy provides an alternative to the tonal and co-phonological account of B\&H, which addresses two central debates in phonological theory: that of a morpheme-based morphological model versus a word/paradigm-based morphological model, and that of a lexical tonal analysis versus a metrical analysis of so-called pitch-accent systems. In the discussion here, we focus on comparing the morpheme-based and the cophonology-approach to allomorphy; for a more detailed general comparison of the tone-based and the metrical analysis of Uspanteko pitch accent, see Köhnlein (2019).

Before continuing the discussion, we should first give a brief overview on B\&H's cophonological approach. They adopt three nominal cophonologies to account for Patterns A1-A3, and argued for an outputoutput faithfulness constraint MAX-OO for Pattern B. The three cophonologies account for the surface exponence by reranking three crucial constraints: a faithfulness constraint against deleting underlying tones, 
MAX-T; a faithfulness constraint against vowel shortening, ID-LENGTH; a markedness constraint against realizing tones on the final syllable, $\operatorname{NonfiN}(T, \sigma)$. The three cophonologies are summarized in (34), with the corresponding pattern number in our analysis:

Three nominal cophonologies in $\mathrm{B} \& \mathrm{H}(\mathrm{H}$ tone $=\mathrm{H}$ of falling pitch accent in our approach):

a. MAX-T, ID-LENGTH $>>\operatorname{Nonfin}(\mathrm{T}, \sigma)-\mathrm{H}$ tone allowed when affixed (Pattern A1)

b. $\operatorname{Nonfin}(T, \sigma)>>$ MAX-T $>>$ ID-LENGTH - Vowel shortening, H tone preserved (Pattern A2)

c. $\operatorname{Nonfin}(T, \sigma)$, ID-LenGth $>>$ MAX-T $-\mathrm{H}$ tone blocked (Pattern A3)

For Pattern B ([kúuk $\left.{ }^{2}\right] \sim\left[\right.$ in.kúuk $\left.\left.^{2}\right]\right)$, B\&H call for an additional faithfulness constraint, MAX-OO to preserve the root $\mathrm{H}$ tone (falling pitch accent) from being deleted or shifted upon affixation. In this sense, they develop a fourth cophonology to account for the stability of stress and pitch accent in Pattern B. Furthermore, as MAX-OO requires parallel evaluations to be run at the same time, it adds an additional level of complexity to the analysis.

We stress a few fundamental differences between our account and that of B\&H: First, B\&H invoke four nominal cophonologies only to account for the affix allomorphy problem for long vowels, while they do not mention what effects these cophonologies could have in simplex words. The four underlying patterns we propose yield the correct surface forms both in isolation or affixed, without the need to make references to different constraint-based grammars. We believe that our morpheme-based approach, which incorporates Kager's (1993) foot inventory and Köhnlein's (e.g. 2016, 2019) approach to metrically conditioned tonal contrasts, offers a more restrictive analysis of the patterns under discussion. In our approach, there is only a restricted number of possible foot structures and tonal patterns, and the Uspanteko patterns appear to exhaust the set of logical possibilities. An approach with lexically indexed cophonologies, on the other hand, does not seem to have a principled limit on how many grammars the language would allow. We are aware that, by using Stratal OT for our complete analysis, we also allow for cophonologies (stem level, word level, phrase level, of which we will 'need' the first two levels); yet still, there is a principled limit to the number of possible cophonologies, unlike in approaches that allow for different constraint rankings based on lexical classes (see, e.g., Bermúdez-Otero 2012 for detailed discussion).

From a broader perspective, our analysis shows that allowing for a more detailed theory of representations makes it possible to account for patterns that at first sight might look like they require referring to cophonologies (or other word- or paradigm-based models of morphology). In that sense, our approach to non-concatenative exponence is in line with principles of autosegmental metrical phonology and Generalized Non-Linear Affixation (Bermúdez-Otero 2012, Trommer \& Zimmermann 2014).

\section{References}

Bennett, Ryan and Robert Henderson (2013). Accent in Uspanteko. Natural Language and Linguistic Theory 31:3. 589645.

Bermúdez-Otero, Ricardo (2012). The architecture of grammar and the division of labor in exponence. In Jochen Trommer (ed.) The morphology and phonology of exponence. Oxford: Oxford University Press. 8-83.

Bermúdez-Otero, Ricardo (2018). Stratal Phonology. In S.J. Hannahs \& Anna R. K. Bosch (Eds.), The Routledge handbook of phonological theory. Abingdon: Routledge. 100-134.

Can Pixabaj, Telma (2006). Gramática descriptiva Uspanteka. Oxlajuuj Keej Maya' Ajtz'iib’ (OKMA).

de Lacy, Paul (2002). The interaction of tone and stress in Optimality Theory. Phonology 19:1. 1-32.

Hayes, Bruce (1995). Metrical stress theory: Principles and case studies. Chicago: University of Chicago Press.

Hermans, Ben (2012). The phonological representation of the Limburgian tonal accents. In Botma, Bert \& Roland Noske (eds.). Phonological Explorations: Empirical, Theoretical and Diachronic Issues. Berlin: Mouton de Gruyter. 227244.

Hyman, Larry. M (2009). How (not) to do phonological typology: The case of pitch-accent. Language Sciences 31. 213238.

Iosad, Pavel (2016). Tonal stability and tonogenesis in North Germanic. In Ian Giles, Chapot Laura, \& Christian Cooijmans, Ryan Foster \& Barbra Tesio (Eds.), Beyond Borealism: New perspectives on the North. London: Norvik Press. 80-97.

Kager, René (1993). Alternatives to the iambic-trochaic law. NLLT 11:3. 381-432.

Kehrein, Wolfgang (2017). There's no tone in Cologne: against tone segment interactions in Franconian. In Kehrein et al. (eds.). 147-194. 
Kehrein, Wolfgang, Björn Köhnlein, Paul Boersma \& Marc van Oostendorp (eds.) (2017). Segmental structure and tone. Berlin: Walter de Gruyter.

Köhnlein, Björn (2011). Rule reversal revisited: Synchrony and diachrony of tone and prosodic structure in the Franconian dialect of Arzbach. Utrecht: LOT. Dissertation Series 274.

Köhnlein, Björn (2016). Contrastive foot structure in Franconian tone accent dialects. Phonology 33:1. 87-123.

Köhnlein, Björn (2019). Metrically Conditioned Pitch Accent in Uspanteko. In Rob Goedemans, Jeffrey Heinz \& Harry Van der Hulst (eds.), The Study of Word Stress and Accent: Theories, Methods and Data. Cambridge: Cambridge University Press. 293-322.

McCarthy, John J. (1995): Extensions of Faithfulness: Rotuman Revisited. Ms., University of Massachusetts Amherst. Rutgers Optimality Archive 110.

McCarthy, John J. (2000). The prosody of phase in Rotuman. NLLT 18:1. 147-197.

McCarthy, John J. \& Alan Prince (1995). Faithfulness and reduplicative identity. In Jill N. Beckman, Laura Walsh Dickey \& Suzanne Urbanczyk (eds.) University of Massachusetts occasional papers in linguistics (Vol. 18). Amherst, MA: GLSA Publications. 249-384.

Móren, Bruce (2001). Distinctiveness, Coercion and Sonority: A Unified Theory of Weight. Outstanding Dissertation in Linguistics series, Garland/Routledge Publishers.

Morén-Duolljá, Bruce (2013). The prosody of Swedish underived nouns: No lexical tones required. Nordlyd 40:1. 196248.

Morrison, Donald Alasdair (2018). Scottish Gaelic svarabhakti: not evidence for prosodic identity in copy epenthesis. Talk presented at the $26^{\text {th }}$ Manchester Phonology Meeting, May $24^{\text {th }}, 2018$, Manchester, UK.

Prince, Alan \& Paul Smolensky (1993). Optimality Theory: constraint interaction in generative grammar. Ms., Rutgers University \& University of Colorado, Boulder. Published 2004, Malden, Mass. \& Oxford: Blackwell.

Saba Kirchner, Jesse (2010). Minimal Reduplication. PhD dissertation, UC Santa Cruz.

Saba Kirchner, Jesse (2013). Minimal reduplication and reduplicative exponence. Morphology 23.2. 227-243.

Trommer, Jochen and Eva Zimmermann (2014). Generalized mora affixation and quantity-manipulating morphology. Phonology 31:3. 463-510. 